\title{
XVI. On molecular shadows in incandescence lamps
}

\section{J.A. Fleming M.A. D.Sc.}

To cite this article: J.A. Fleming M.A. D.Sc. (1885) XVI. On molecular shadows in incandescence lamps, Philosophical Magazine Series 5, 20:123, 141-144, DOI: 10.1080/14786448508627735

To link to this article: http://dx.doi.org/10.1080/14786448508627735

曲 Published online: 29 Apr 2009.

Submit your article to this journal $\pi$

Џ Article views: 3

Q View related articles ¿ 
XVI. On Molecular Shadows in Incandescence Lamps. By J. A. Fleming, M.A., D.Se. (Lond.), Fellow of St. John's College, Cambridge, Professor of Electrical Technology in University College, London* .

QINCE presenting a short note on the above subject in 1883 many further opportunities have occurred for observing the conditions under which molecular shadows are formed in incandescence carbon-filament lamps, and of correcting one or

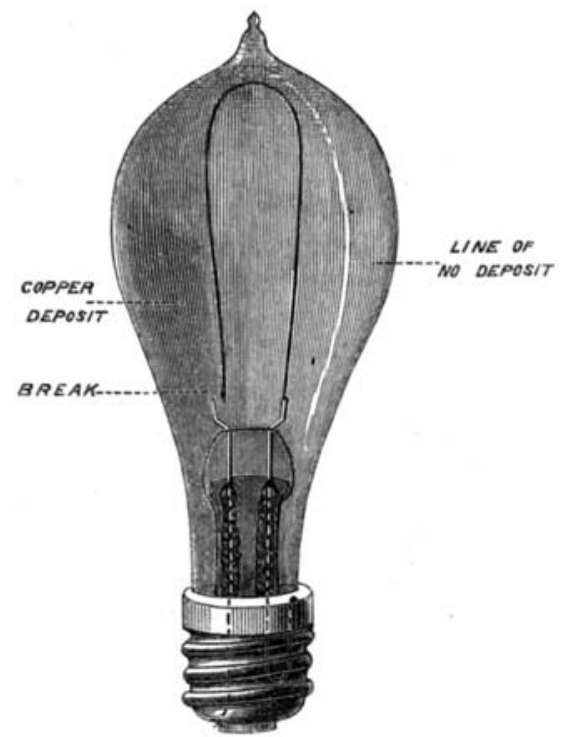

two statements then made. It has been observed in an immense number of cases, that not only do incandescence lamps become coated on the interior of the glass with a deposit of carbon, but that the envelope may have deposited upon it a metallic film, derived from the leading-in wires to which the carbon flament is clamped. In the Edison lamp the platinum wire only just passes through the glass, and is connected with copper wires broadened out into a clamp; the filament is gripped in these clamps and then electro-plated over with copper to effect a good junction. In the Swan lamp the platinum wires are joined directly on to the carbon. It occasionally happens that there is an unusual amount of resistance at the clamps, or that by excessive electromotive force more current is forced through the lamp and more heat gene-

* Communicated by the Physical Society : read June 27, 1885. 
rated everywhere. In this case the tendency will always be to increase and go on increasing the resistance, and, therefore, the temperature at the point of highest resistance. Suppose this occurs on the clamp or on the leading-in wire, then experience shows that the metal is volatilized and deposited as a film on the glass. This metallic deposit is not uniform ; it is thickest nearest the base of the lamp and gradually thins away up to the crown, and at a certain height is thin enough to transmit light. It is not very uncommon to obtain Edison lamps with this copper deposit. The colour of transparent copper is a fine sage green inclining to blue; compared with the colour of gold leaf seen by transmitted light, it very closely resembles it. On one occasion the writer obtained $x$ lamp with a silvery metallic film deposited over it on the inside of the glass. From the outside it had a mirror-like lustre; on breaking the lamp this film was seen to be brownish and not brushed off by the finger, but it could be removed by scratching. It was not removed by holding in the oxidizing flame of a Bunsen burner: therefore it was not carbon. It was not removed by nitric acid; but on boiling a fragment of the glass, covered with this metallic deposit, in nitro-hydrochloric acid the film disappeared. It was therefore probably platinum. The film was transparent, permitting objects to be seen through it, and transmitted brownish light.

Now, under certain circumstances, a line of no deposit is formed on the surface in the plane of the filament, which is, as it were, the shadow of one side of the loop This indicates that the process of molecular scattering, which is going on at some spot on one or other clamp, is not a mere evaporation or volatilization of the metal, but a projection of molecules in straight lines in every direction. The trajectory of the molecules will be interfered with in some directions by the carbon filament; and hence result lines and places of no deposit which are molecular shadows of the loop. On every other part of the glass the molecules will inpinge and adhere, forming a metallic coating. From the facts that the free paths of the molecules differ in length, and that the clamp is much nearer to the neck of the lamp than to the crown, it follows that a much larger proportion of the scattered molecules strike the glass near the neck, and the thickness of the deposit is therefore a measure of the proportion of molecules which have a free path, equal to the distance of that part of the envelope from the scattering point. Curiously enough the line of no deposit, or shadow of the loop, is not always seen in copperdeposited lamps. This may be because the scattering is going on from both elamps, and therefore the shadow on one 
side is covered up by the shower from the clamp on that side. It has been noticed in one or two cases that small tufts of carbon are seen on one clamp, and that when a well-defined shadow exists on that side, this seems to indicate that the shower of copper molecules has been partly stopped by the opposite clamp, which has therefore acted like a target and become encrusted with a proportion of the molecules shot at it.

With respect, next, to carbon deposits. Every one knows the appearance of a lamp after it has been burning for some time or overburnt: it is clouded with smoke-like deposit. In nearly all cases of copper deposit the molecular shadow exists, but it is not nearly so often seen in the case of carbon deposits. After many observations it was found that the molecular shadow of the filament, or line of no deposit, could be formed by suddenly raising the filament to a very high temperature, as for instance by placing a 50-volt lamp for an instant on a 100-volt circuit; whereas when the deposit of carbon takes place slowly, and as it were in the natural way, the lamp exhibits only a general smokiness but no line. Again, it has been found that when a carbon filament is cut sharply through at one point, caused by excessive temperature at one spot, there is very frequently a sharply marked line of shadow of the loop on the side of the envelope farthest removed from the fracture. These facts seem to indicate that in normal use, when the lamp is not being pressed beyond the electromotive force at which it was intended to be used, there is a general evaporation of carbon going on from all parts of the loop, and these molecules, being projected with no abnormal velocity, probably collide with molecules of residual air a large number of times before they reach the walls of the envelope, and thus get their trajectories very much changed in direction. In this case the result would be to cause an irregular deposit of molecules of carbon on the glass envelope. But if we suppose a sudden or very excessive temperature to be given to part or the whole of the filament, this may cause a very violent projection of molecules of carbon from the filament; and these would pass outwards in straight lines, and a far larger proportion would reach the envelope in the direction in which they were first projected. This would then cause a deposit on all parts except those shielded by the loop ; and in the case when such violent projection went on from all parts of the loop, as when a lamp is overheated, it is easily seen that parts of the envelope not lying exactly in the plane of the filament would receive twice as much deposit as those exactly in the plane. In most cases of carbon deposits the lamps 
which give the best shadows are those made with single loop, but it has also been observed on Swan lamps with double twist. By making lamps with clamps of various metals, it might be possible to obtain metallic films of various kinds. Interesting magneto-optic phenomena might perhaps present themselves in the case of transparent iron films, if they could be obtained.

XVII. Origin of Coral Reefs and Islands. By James D. Dana, LL.D.*

[Plate I.]

7 HE Presidential Address of Dr. Archibald Goikie, Director-General of the Geological Survey of Great Britain, before the Royal Physical Society of Edinburgh in $1883 \mathrm{t}$, reviews the subject of the origin of coral-reefs and islands. In the course of the discussion, the author sustains and enforces the objections which have been presented by others, and concludes that "the existence of such reefs is no more necessarily dependent on subsidence than on elevation." The existing state of doubt on the question has led the writer to reconsider the earlier and later facts, and in the following pages he gives his results $\ddagger$. That both sides may be fairly before the reader, the views of Darwin and the evidences in favour of his theory are first considered, and afterwards the arguments that have been urged against it. Part of the objections are based on misunderstandings of the facts, and hence a general presentation of the subject has been thought necessary.

\section{PART I.-The Darwinian Theory and its Evidences.}

1. According to the Darwinian theory, islands with fringing reefs have been often changed through a slow subsidence of the region into islands with barrier reefs; and, as the last summit of the sinking land disappeared, the latter have become atolls, that is, barrier reefs enclosing simply a piece of the ocean (or a lagoon). Darwin added to this conclusion, a second, in view of the wide distribution of atolls and their

* From an advance proof from Silliman's 'American Journal,' communicated by the Anthor, to whom we are also indebted for copies of the plate and cliches of the woodcuts.

+ Proceedings Edin. Roy. Phil. Soc. viii. p. 1 (1883).

I The writer's account of his original observations is contained in his Wilkes Expedition, Geological Report, 1849 (756 pp. 4to), pp. 29-154; and, less completely, along with a review of facts from other regions, in his 'Corals and Coral Islands;' 398 pp. 8vo (1872, 1875). 